\title{
Covid-19: retired doctors could be asked to return to work, says Hancock
}

\author{
Elisabeth Mahase
}

The BMJ

Recently retired doctors may be asked to return to work as part of the UK's covid-19 response, according to health secretary Matt Hancock.

Speaking on The Andrew Marr Show on 1 March, Hancock said this option is being considered, but that it was "not something we need right now."

The government is currently developing contingency plans-expected later this week-and prime minister Boris Johnson will chair a meeting of the COBRA emergency committee today (2 March). So far, 40 people in the UK have tested positive for the virus.

"The big challenge for the NHS in the event of covid-19 becoming widespread is NHS staff not being able to come to work because they are ill or self-isolating. It is not so much about physical buildings, it's about the people," Hancock said. His comments came as GPs raised concerns over their lack of personal protective equipment (PPE). Posting on social media, South Cumbria GP Alison Johnston asked Hancock, "What are you doing to protect GPs from coronavirus outbreak? Currently we have two masks for the whole surgery and no full PPE or training in how to use PPE. What will happen to our patients when we catch it?"

Other commentators asked what protection healthcare professionals with long term conditions will get. ${ }^{1}$

Hancock said, "There are, right now, huge protection measures that are in place for current cases, and we are putting measures in place for future cases. We are buying, at speed, the sorts of kit we need. Also, some of the stock that we stored in case of a no deal Brexit is being used."
He was then questioned on reports that there are only nine to 11 beds across England vacant for people who may need ventilators if seriously ill with covid-19. Hancock said the figures were "wrong and out of date."

Pressed on how many ventilators the UK has, he continued, "We have 50 now and we can ramp that up to 500 and then if necessary 5000." He specified, however, that those would be 5000 beds "that are able to cope with the worst impact of this virus" rather than 5000 beds with ventilators.

When asked about whether elective surgery may be cancelled because beds are being used for covid-19 instead, Hancock said, "Of course I do not want to do that, but these are clinical decisions. Clinicians have to make decisions about what is the most important and effective use of NHS resources."

As of 2 March, the worldwide death toll for covid-19 has exceeded 3000. Nearly 90000 people have been infected in more than 60 countries, with around 80000 in China.

In South Korea, the government has announced it will investigate religious sect leader Lee Man-hee, the founder of the Shincheonji Church, and 11 others in relation to coronavirus deaths. They were accused of hiding the names of members as officials tried to track patients before the virus spread. The country had reported more than 4000 cases and 21 deaths, with more than half of all infections involving members of the church. Meanwhile in the US, a second death has been recorded. There are 88 confirmed cases in the country.

Johnston A. Twitter. March 2020. twitter.com/dralisonj/status/1234105297695858688. Published by the BMJ Publishing Group Limited. For permission to use (where not already granted under a licence) please go to http://group.bmj.com/group/rights-licensing/ permissions 